\title{
Vasculitides in HIV Infection
}

\author{
Luis E. Vega ${ }^{1} \cdot$ Luis R. Espinoza ${ }^{2}$ \\ Published online: 26 August 2020 \\ (C) Springer Science+Business Media, LLC, part of Springer Nature 2020
}

\begin{abstract}
Purpose of Review To review the spectrum of vasculitides in HIV-infected patients and to identify the clinical features that characterize vasculitis in sero-positive HIV.

Recent Findings Epidemiological studies conducted in the post-HAART era described the rarity of vasculitis in the setting of HIV-infected patients. A study identified histopathological features such as leukocytoclastic vasculitis of the vasa vasorum and adventitial inflammation in the large artery pathology of HIV-positive patients compared with HIV-negative patients with critical lower limb ischemia. A recent retrospective cohort study reported that HIV-positive patients with LVV developed more vascular complications, responded less to antiretroviral therapy, and had worse outcome than HIV-negative patients with LVV.

Summary Vasculitides continue to be a rare disease in patients with HIV. The spectrum of vasculitis ranges from life-threatening conditions to relatively mild skin conditions. Recognizing vasculitis in the setting of HIV-positive patients is important because sometimes it require immunosuppressive treatment.
\end{abstract}

Keywords HIV infection $\cdot$ Vasculitides $\cdot$ Polyarteritis nodosa $\cdot$ Kawasaki-like syndrome $\cdot$ Large-vessel vasculitis

\section{Introduction}

At the time of writing, the world grapples with the pandemic of COVID-19, each day passing continues to increase the number of lives lost and the human suffering. Nearly 40 years have elapsed since the occurrence of HIV pandemic which caused high mortality among affected population [1]. An analogous situation such as stigmas, diagnostic testing, and treatment almost similar to the beginning of the HIV pandemic is the one we are seeing in this new global medical emergency due to the pandemic caused by infection with SARS-CoV-2 coronavirus (COVID-19) [2]. The immunodeficiency status of patients with HIV/AIDS was accompanied by the occurrence of inflammatory and autoimmune diseases and is an

This article is part of the Topical Collection on Vasculitis

Luis E. Vega

luisenvega@gmail.com

1 Section of Rheumatology, Air Force Central Hospital, Aramburú Ave 2nd block, Lima, Peru

2 Louisiana State University Health Sciences Center, 433 Bolivar St, New Orleans, LA 70112, USA issue that needs to be kept in mind and that their development still is an enigma.

\section{Epidemiology}

Reliable studies on the prevalence of HIV-associated vasculitis are scarce because there are few high-quality, descriptive, longitudinal, and cohort studies. There are prevalence data from studies that have been conducted in hospitals, but this is not a true representation of what occurs in the general population.

Vasculitis has been uncommonly associated with HIV infection, and the literature have reported a frequency $<1 \%$ [3].

Contrary to these data, Zhang et al. in a study conducted in Asian patients infected with HIV/AIDS showed higher prevalence of vasculitis in 20 cases of vasculitis $(20.41 \%)$ in 98 inpatients with HIV/AIDS, including Behçet-like disease $(n=$ $15)$, Henoch-Schonlein purpura $(n=2)$, digital gangrene $(n=$ 2 ), and central nervous vasculitis $(n=1)$. This raises the question of whether ethnicity plays an important role in the development of prevalent rheumatic manifestation [3, 4•]. Yao et al. have not reported cases of vasculitis in a retrospective record review of 888 inpatients with HIV/AIDS [5]. Yen et al. and Lebrun et al. conducted prospective longitudinal cohort study 
during highly active antiretroviral therapy (HAART) era, and both did not show development of vasculitis cases $[6 \bullet 7 \bullet]$.

J. Reveille (personal communication, May 24, 2020) reported a retrospective chart review of HIV-infected patients evaluated at an outpatient rheumatology clinic from 1994 to 2019.The frequency of vasculitides was $0.9 \%$. The spectra of vasculitides were as follows: systemic vasculitis/polyarteritis nodosa $(n=3)$, granulomatosis with polyangiitis $(n=2)$, primary angiitis of the CNS $(n=2)$, MPO-associated vasculitis $(n=1)$, IgA vasculitis $(n=1)$, and HCV-associated cutaneous vasculitis $(n=1)$.

In the last 10 years of the post-HAART era, there has been an absence of new cases of vasculitis and this is probably due to a more effective antiretroviral treatment $[4 \bullet]$.

\section{Mechanisms to Induce Vasculitis in HIV Infection}

The pathogenic mechanisms of these diseases are not completely understood; however, there are proposed mechanisms that may cause vascular damage: (1) direct action, vascular wall injury by HIV replication or opportunistic microorganism; (2) indirect action, formation and depot of immune complexes (molecular mimicry); (3) the aberrant immune activation which characterizes the HIV infection could act indirectly in the development or maintenance of the vascular inflammatory reaction [8, 9]; and (4) other mechanism is immune restoration inflammatory syndrome during HAART that suggests that immunopathology results from restoration of protective pathogen-specific cellular immune response [3, 10] (see Fig. 1).

\section{Clinical Manifestations}

The clinical manifestations of patients with HIV vasculitis are wide and depend of the size of the compromised blood vessel and can occur at any stage of HIV infection; therefore, the spectrum and severity of vasculitides range from lifethreatening disease to relatively minor skin disease.

\section{Small Vessel Vasculitis}

The common denominator of these affectations is usually cutaneous involvement presenting as palpable purpura and less frequently extracutaneous involvement, which is less severe compared with other vasculitis forms.

\section{Hypersensitivity Vasculitis}

The reported cases are most often induced by antiretroviral drugs and less post infectious [11]. Because HIV/AIDS patients take a combination of antiretrovirals, often determining the cause of a cutaneous eruption can be difficult.
Fig. 1 Mechanisms to induce HIV infection

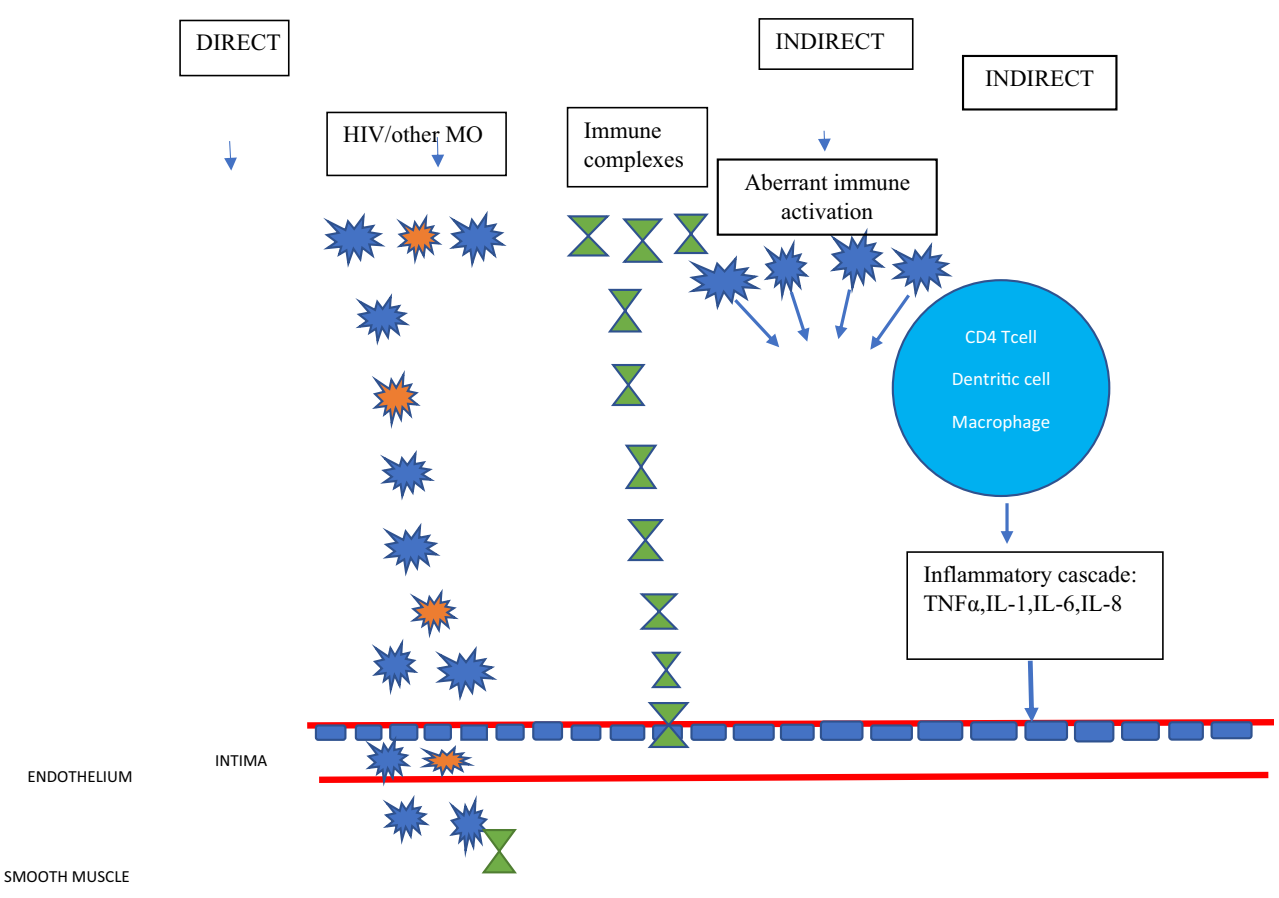




\section{Erythema Elevatum Diutinum}

A rare form of leukocytoclastic vasculitis of the skin is EED associated with progressive fibrosis. HIV disease is likely to predispose to this disorder. Many published literature report associations between CD4 and EED. CD4 count of less than $300 \mathrm{cells} / \mu \mathrm{l}$. to be a risk factor for EED. The lesions initially are soft, non-fixed red/violaceous, or brown papules and nodules that later become firm because of fibrosis [12-15]. Patient responded well to dapsone treatment [15].

\section{Mixed Cryoglobulinemia}

HIV infection is a recognized cause of mixed cryoglobulinemia. Previous studies have reported the prevalence of cryoglobulins varying from 17 to $27 \%$ [16]. MC is frequently associated with infectious agents such as CMV, EBV, and hepatitis $\mathrm{C}$ virus. Clinical manifestations are like HIV-negative individuals, but many times, vasculitis purpura is not seen, and the clinical picture is predominantly neurologic [17].

\section{Vasculitis of the Central Nervous System}

Vasculitis of the CNS is an uncommon disease. In the setting of HIV/AIDS, CNS vasculitis may be primary or are associated with concomitant infection by opportunistic or noopportunistic microorganisms. Primary vasculitis of the CNS is a diagnosis of exclusion [18]. Melica et al. reported cases of primary vasculitis of CNS, in African patients suggesting ethnic predisposition. The patients showed persistently low CD4 cell counts, and two of these patients had been receiving HAART and had partial or good control of viral replication, suggesting persistent immune activation [19]. Benjamin et al. conducted a study of adult ischemic stroke. They made comparison between HIV-infected and non-infected HIV patients and found that HIV-associated vasculitis was one of the etiologies. Patients were younger, at late stage of HIV/AIDS, and have fewer risk factors for stroke. Most cases started on HAART suggestive of immune reconstitution inflammatory syndrome [20]. It has been described coinfection with CMV, $\mathrm{VZV}$, toxoplasmosis [21, 22].

\section{Medium-Sized Vessel}

\section{Polyarteritis Nodosa}

A form similar has been described in patients infected with HIV and named polyarteritis nodosa-like disease (PAN-LD). The classic PAN is associated with hepatitis B virus and is characterized by inflammation and necrosis predominantly medium-sized vessels, typically involving renal and other visceral arteries while sparing the pulmonary circulation, while HIV-associated PAN compromises smaller and/or mediumsized vessels of the skin, muscle, nerves, and gastrointestinal tract with rare involvement of the renal arteries [23, 24]. PAN can occur at any stage of HIV/AIDS disease and at any count of CD4. The clinical course of HIV-related PAN exhibits major differences in comparison with classic HBV-related PAN (see Table 1). Presence of anti-neutrophil cytoplasmic antibodies, especially pANCA, is high (13-42\%), but its clinical significance is not well defined.

\section{Kawasaki-Like Syndrome}

Classic Kawasaki (KD) disease is a multisystem disorder, affects most frequently children, and is rarely seen in adults $[25$, 26]. This disease commonly compromise coronary arteries and can lead to various complications like coronary artery aneurysm, thrombosis, stenosis and even sudden.

KLS occurs in association with moderate to severe immunodepression, low CD4 count, and high viral load [27•]. It is probably that KD and KLS are the same disease because they share inflammatory signature such as soluble tumor necrosis factor receptor (sTNFRII) and chemokines Cd11, Cdl2, and Cxcl11 [28]. Compared with KD is not reported coronary aneurysm [29] (see Table 2). Also KLS has been described after the introduction of HAART, as a potential form of IRIS. The therapy is the same with classic KD [30].

\section{Large-Vessel Vasculitis}

The spectrum of large-vessel disease associated vasculitis consists of aneurysms and occlusive disease [31]. This disorder can occur in the absence of known risk factors such as
Table 1 Differences between HIV-PAN and classic PAN

\begin{tabular}{lll}
\hline & HIV-associated PAN & Classic PAN \\
\hline Virus associated & None & HBV \\
Involvement & Rare multisystem & Multisystemic \\
Common symptoms & Peripheral neuropathy, rash & Fever, livedo reticularis, cardiac, \\
Clinical course & gastrointestinal, and renal \\
\hline
\end{tabular}


Table 2 Comparison of clinical symptoms and laboratory abnormalities in Kawasaki disease of HIV-positive and HIV-negative adults and children

\begin{tabular}{llll}
\hline & HIV & HIV & Children \\
\hline Conjunctivitis & ++++ & ++++ & +++++ \\
Pharyngitis & +++ & ++++ & ++++ \\
Cheilitis & +++ & +++ & ++++ \\
Stomatitis & +++ & ++++ & +++++ \\
Desquamation & +++++ & +++++ & +++++ \\
Adenopathy & +++++ & +++++ & +++++ \\
Arthralgia & ++ & ++ & ++ \\
Gastrointestinal & +++ & ++ & ++ \\
Electrocardiogram abnormalities & + & + & +++ \\
Coronary aneurysms & - & $-/+$ & +++ \\
Leukocytosis & + & ++ & \\
Thrombocytosis & + & +++ & +++++ \\
Risk of relapse & ++ & $-/+$ & $-/+$ \\
\hline
\end{tabular}

arterial hypertension, diabetes mellitus, and atherosclerosis. There is also evidence to suggest that HIV infection promotes the development of accelerated atherosclerosis due to endothelial damage occurring in a much younger group of patients and could be associated to vasculopathy [31].

LVV is uncommon. The patients more affected tend to be young, in advanced stages of diseases, and present more severe vascular complications such as aneurysms and occlusive disease [31]. The patients were predominantly black African. The aneurysms or occlusions are usually multiple [31,32•]. A particularity is that the aneurysms are in atypical locations such as carotid, subclavian, femoral, and popliteal vessels $[31,32 \cdot]$. The main histopathologic finding is leukocytoclastic vasculitis of the vasa vasorum and of periadventitial vessels [33•]. Other histopathologic findings will depend on the stage of disease (see Table 3). Clinical and histopathological characteristics overlap or are reminiscent with those seen in Takayasu arteritis (TA) [33•, 34, 35••]. Vasculitis resulting from IRIS is extremely rare, unless an associated opportunistic infection is present.

Robbs performed a study in 226 patients admitted with HIV vasculopathy and reported vascular complication such as aneurysms in 111 patients and occlusive disease in 115 ones. Patients were predominantly man, younger, and black African. The CD4 count was low (range 1-930 cells $/ \mathrm{mm}^{3}$ ) [36].

Ferfar et al. performed a retrospective cohort study with 93 patients affected of LVV. Eleven patients (12\%) also had HIV infection [35••]. Patients were middle-aged adults. Most patients fulfilled Ishikawa or ACR criteria of TA diagnosis. Histopathologic examinations showed changes like TA. These patients were compared with their HIV-negative counterparts. Patients with LVV-HIV developed more vascular complications, 6 patients with aneurysms, and 5 with vascular occlusion, and there was significantly greater use of vascular procedures. They also indicated that corticosteroids and immunosuppressive therapy were less often prescribed in HIVpositive patients and had worse outcome than non-HIV patients with LVV.

The vasculitis may occur in all ranges of $\mathrm{CD} 4$, independent of viral load, and in patients after starting antiviral therapy suggesting an immune reconstitution inflammatory syndrome (IRIS) [35••, 36, 37]. A further observation was the lower use of conventional and biological DMARD in patients with HIVassociated vasculitis.

\section{Other Vasculitis}

Behcet's Disease The rare cases occurred in the setting of an acute HIV infection characterized by a high viral load, and these symptoms decreased following initiation of effective antiretroviral therapy and a rapid decreased of virologic load. Researchers have postulated that induction of Behcet's disease in HIV-associated cases might be a direct effect of viral replication or through HIV induction of autoimmune mechanisms or immune dysregulation $[38,39]$.

\section{Therapy}

\section{Controlling the HIV Infection}

HAART forms an essential part of the therapy to prevent disease progression. The early use of currently available antiretroviral drug (HAART) could avoid the catastrophic
Table 3 Histopathologic findings in LVV-associated vasculitis

\begin{tabular}{|c|c|c|}
\hline Intima & Media & Adventitia \\
\hline \multirow[t]{4}{*}{$\begin{array}{l}\text { Duplication and } \\
\text { fragmentation of the } \\
\text { internal elastic lamina }\end{array}$} & Fragmentation of the elastic tissue & $\begin{array}{l}\text { Marked leukocytoclastic } \\
\text { vasculitis of the vasa vasorum } \\
\text { and periadventitial vessels }\end{array}$ \\
\hline & Medial necrosis & $\begin{array}{l}\text { Proliferation of slit-like } \\
\text { vascular channels }\end{array}$ \\
\hline & $\begin{array}{l}\text { Plasmolymphocitary and } \\
\text { giant cell infiltrate }\end{array}$ & Chronic inflammation \\
\hline & Fibrosis & Fibrosis \\
\hline
\end{tabular}


complications of large-vessel vasculitis such as aneurysms and occlusion.

\section{Treating the Vasculitis}

Deciding how to treat the HIV-associated vasculitis is not easy, because the pathogenesis is not completely understood.

HIV infection has significantly impacted the natural history and therapeutic intervention of autoimmune diseases due to the presence of underlying immunosuppression and the use of immunosuppressive drugs or biologic agents that may lead to serious complications including infections.

\subsection{Management of Vasculitis Secondary to Drugs and Infectious Agents}

The resolution occurs with discontinuation of the offending agent and treatment with oral corticosteroid in the first case and administration of antibiotics in the second case.

\subsection{Management of Severe Vasculitis Diseases}

The array of therapeutic agents is similar in HIV-positive and HIV-negative patients [40-42]. Patients afflicted with HIV-associated vasculitides may respond well to conventional therapy such as corticosteroids and DMARDs including methotrexate, leflunomide, mofetil mycophenolate, azathioprine, and cyclophosphamide, and for refractory cases may need the use of biological agents such as rituximab, tocilizumab. When considering immune suppressive therapy, it is important to keep in mind that CD4+ T cells are necessary in the control of intracellular and extracellular bacteria, parasites, and viruses. This therapy should be recommended when patients have CD4+ T cell counts above 200 cells $/ \mathrm{mm}^{3}$ and HIV viral activity completely suppressed to $<60,000$ copies $/ \mathrm{mm}^{3}[43,44]$. In addition, they have been shown to be effective, safe, and well-tolerated [44].

Currently, however, there are no studies of good quality on the use of biologic therapy to vasculitis disorders in HIVinfected patients; therefore, we cannot conclude on efficacy and safety of biologic therapies in HIV-infected populations.

As part of the proposed measures to improve the management of rheumatic patients in times of COVID-19, it is not advisable to discontinue immunosuppressive treatment as it may be responsible for onset of clinical flare of rheumatic disease [45].

\section{Managing the Aneurysms and Occlusive Disease}

These complications are considered emergencies and therefore should be prioritized regardless of the immune status. Treatment should be individualized and prioritized to patients with symptomatic aneurysmal lesion and acute arterial occlusion [31, 32•, 36, 37]. Interventional or surgical therapy is indicated if a vascular lesion that persists despite medical therapy is either symptomatic or is associated with an increased risk of future complications.

The therapeutic decisions will always require the participation of a cardiovascular surgeon. Management of HIVassociated vasculitis requires a multi-disciplinary approach where intervening rheumatologist, vascular surgeon, and rehabilitation specialists.

Prophylaxis Consensus suggests that prophylaxis against opportunistic infection should be given to all HIV patients on immunosuppressive therapy due to an increase risk of infection.

\section{Conclusions}

Vasculitides is a group of rare diseases that affect large, medium, and small vessels. It is a clinically important complication that we must recognize because it requires immunosuppressive treatment. Interventional or surgical therapy will be reserved for patients with complicated large-vessel vasculitis.

\section{Compliance with Ethical Standards}

Conflict of Interest The authors declare that they have no conflict of interest.

Human and Animal Rights and Informed Consent This article does not contain any studies with human or animal subjects performed by any of the authors.

\section{References}

Papers of particular interest, published recently, have been highlighted as:

- Of importance

•. Of major importance

1. UNAIDS. Fact sheet-latest statistics on the status of the AIDS epidemic 2016. http://www.unaids.org/en/resources/fact-sheet (access September 23, 2017).

2. Logie $\mathrm{CH}$. Lessons learned from HIV can inform our approach to COVID-19 stigma. J Int AIDS Soc. 2020;23:e25504.

3. Zhang X, Li H, Li T, Zhang F, Han Y. Distinctive rheumatic manifestations in 98 patients with human immunodeficiency virus infection in China. J Rheumatol. 2007;34:1760-4.

4. Vega LE, Espinoza LR. Human immunodeficiency virus infection (HIV)-associated rheumatic manifestations in the pre- and postHAART eras. Clin Rheumatol. 2020. https://doi.org/10.1007/ s10067-020-05082-8. A recent review about HIV-associated rheumatic manifestation in the pre-and post-HAART eras.

5. Yao Q, Frank M, Glynn M, Altman RD. Rheumatic manifestations in HIV-1 infected in-patients and literature review. Clin Exp Rheumatol. 2008;26:799-806. 
6. Yen Y-F, Chuang P-H, Jen I-A, Chen M. Incidence of autoimmune disease in nationwide HIV/AIDS patient cohort in Taiwan, 200 2012. Ann Rheum Dis. 2017;76:661-5. This is a study that investigated incidences of autoimmune diseases among people living with HIV/AIDS in Taiwan ,2000-2012.

7. Lebrun D, Hentzien M, Cuzin L, Rey D, Joly V, Cotte L, et al. Epidemiology of autoimmune and inflammatory diseases in a French nationwide HIV cohort. AIDS. 2017;31:2159-66. This study conducted in a large French multicenter cohort estimated the prevalence of Autoimmune and inflammatory diseases among people living with HIV from 2000 to 2013.

8. Ntusi NBA, Taylor D, Naidoo NG, Mendelson M. Progressive human immunodeficiency virus-associated vasculopathy: time to revise antiretroviral therapy guidelines? Cardiovasc J Afr. 2010;21:197-200.

9. Abdurakhmanov A, Zandman-Goddard G. HIV Spectrum and autoimmune diseases. In: Shoenfeld Y, Agmon-Levin N, Rose NR, editors. Infection and Autoimmunity: Academic Press; 2015. p. 371-92.

10. Anderson AM, Fountain JA, Green SB, Bloom SA, Palmore MP. Human immunodeficiency virus-associated cytomegalovirus infection with multiple small vessel cerebral infarcts in the setting of early immune reconstitution. J NeuroVirol. 2010;16:179-84.

11. Bennetta BS, Mikaberidzeb N, Ahmadic LM. A case of dolutegravir-induced cutaneous small vessel vasculitis. AIDS. 2019;33:1804

12. Logan S, and Sontheimer R, MD. Concurrence of erythema elevatum diutinum and HIV infection: a case report and literature review. JAAD Case Rep 2019; 5: 1093-1096.

13. Sheethal KJ, Yogesh M. Erythema elevatum diutinum in acquired immune deficiency syndrome: Can it be an immune reconstitution inflammatory syndrome? Indian J Sex Transm Dis AIDS. 2016;37: $81-4$.

14. Cardis M.A., Sowash M.G., Mosojane K.I., Kovarik C. HIVassociated erythema elevatum diutinum: a case report and review of a clinically distinct variant. Dermatol Online J. 2018;24(5).

15. Al Abadie MS, Tariq A, Frankiewicz J. Treatment of erythema elevatum diutinum in HIV-positive Afro-Caribbean patient. J Am Acad Dermatol. 2012;66:AB134.

16. Kosmas N, Kontos A, Panayiotakopoulos G, Dimitrakopoulos A, Kordosis T. Decreased prevalence of mixed cryoglobulinemia in the HAART era among HIV-positive, HCV-negative patients. J Med Virol. 2006;78:1257-61.

17. Genet P, Courdavault L, Wifaq B, Gerbe J. Symptomatic mixed cryoglobulinemia during HIV primary infection: a case report. Case Rep Infect Dis. 2011;2011:525841.

18. Hajj-Ali RA, Calabrese LH. Diagnosis and classification of central nervous system vasculitis. J Autoimm. 2014;48-49:149-52.

19. Melica G, Brugieres P, Lascaux A-S, Levy Y, Lelievre J-D. Primary vasculitis of the central nervous system in patients infected with HIV-1 in the HAART era. J Med Virol. 2009;81:578-81.

20. Benjamin LA, Allain TJ, Mzinganjira H, Connor MD, Smith C, Lucas $\mathrm{S}$, et al. The role of human immunodeficiency virusassociated vasculopathy in the etiology of ischemic stroke. J Infect Dis. 2017;216:545-53.

21. Amui NO, Silva RGF, Costa DMC, Barsottini OGP, Pedroso JL, Ferreyra PRA. Central nervous system vasculitis in a patient with HIV infection: a diagnostic challenge. Arq Neuropsiquiatr. 2017;75:897-8.

22. Gutierrez J, Ortiz G. HIV/AIDS patients with HIV vasculopathy and VZV vasculitis. Clin Neuroradiol. 2011;21:145-51.

23. Roszkiewicz J, Smolewska E. Kaleidoscope of autoimmune diseases in HIV infection. Rheumatol Int. 2016;36:1481-91.

24. Gajera A, Kais S. HIV polyarteritis nodosa-like vasculitis presenting as chronic abdominal pain. Clin Rheumatol. 2009;28:869-72.
25. Sánchez-Manubens J, Bou R, Anton J. Diagnosis and classification of Kawasaki disease. J Autoimm. 2014;48-49:113-7.

26. McCrindle BW, Rowley AH, Newburger JW, Burns JC, Bolger AF, Gewitz M, et al. American Heart Association Rheumatic Fever, Endocarditis, and Kawasaki Disease Committee of the Council on Cardiovascular Disease in the Young; Council on Cardiovascular and Stroke Nursing; Council on Cardiovascular Surgery and Anesthesia; and Council on Epidemiology and Prevention Diagnosis, Treatment, and Long-Term Management of Kawasaki Disease. Circulation. 2017;135:e927-99.

27. Rivas-Larrauri F, Aguilar-Zanela L, Castro-Oteo P, RosalesHernandez LA, Otero-Mendoza F, López-Herrera G, et al. Kawasaki disease and immunodeficiencies in children: case reports and literature review. Rheumatol Int. 2019;39:1829-38. A literature review about immunodeficiencies complicated with KD.

28. Johnson RM, Bergmann K, Manaloor JJ, Yu X, Slaven J, Kharbanda AB. Pediatric Kawasaki disease and adult human immunodeficiency virus Kawasaki-like syndrome are likely the same Malady 2016. Open Forum Infect Dis. 2016;3:ofw160. https://doi. org/10.1093/ofid/ofw160.

29. Stankovic K, Miailhes P, Bessis D, Ferry T, Broussolle C, Seve P. Kawasaki-like syndrome in HIV-infected adults. J Infect. 2007;55: 488-94.

30. Denby KJ,Clark DE, Markham LW.Management of Kawasaki disease in adults. Heart 2017; 0:1-9. doi:https://doi.org/10.1136/ heartjnl-2017-311774, 103.

31. Pillay B, Ramdial PK, Naido DP. HIV-associated large-vessel vasculopathy: a review of the current and emerging clinicopathological spectrum in vascular surgical practice. Cardiovasc J Afr. 2015;26: 70-81.

32. Genga E, Oyoo O, Adebajo A. Vasculitis in Africa. Curr Rheumatol Rep. 2018;20:4-9. It is a brief description of the vasculitis associated with HIV in Africa.

33. Brand M, Woodiwiss AJ, Michel F, Nayler S, Veller MG, Norton GR. Large vessel adventitial vasculitis characterizes patients with critical lower limb ischemia with as compared to without human immunodeficiency virus infection. PLOS ONE. 2014;9:e106205. This study aimed to identify the histopathologic characteristics in LVV associated HIV.

34. de Souza AW, de Carvalho JF. Diagnostic and classification criteria of Takayasu arteritis. J Autoimmun. 2014;48-49:79-83.

35.• Ferfar Y, Savey L, Comarmond C, Sadaghianloo N, Garrido M, Domont F. Large-vessel vasculitis in human immunodeficiency virus-infected patients. J Vasc Surg. 2018;67:1501-11. The most recent report conducted between 2000-2015 to describe largevessel vasculitis in patients with HIV infection.

36. Robbs JV, Paruk N. Management of HIV vasculopathy - a South African experience. Eur J Vasc Endovasc Surg. 2010;39(Suppl 1): S25-31.

37. Silvestri V, D'Ettorre G, Borrazzo C, Mele R. Many different patterns under a common flag: aortic pathology in HIV-A review of case reports in literature. Ann Vasc Surg. 2019;59:268-84.

38. Roscoe C, Kinney R, Gilles R, Blue S. Behcet's disease diagnosed after acute HIV infection: viral replication activating underlying autoimmunity? Int J STD AIDS. 2014;26:432-5.

39. Siddiqui B, Fernandes D, Chaucer B, Chevenon M, Nandi M, Saverimuttu J, et al. Behcet's disease in acquired immune deficiency syndrome. ID Cases. 2016;3:3-4.

40. Forbess L, Bannykh S. Polyarteritis Nodosa. Rheum Dis Clin N Am. 2015;41:33-46.

41. Yates M, Watts RA, Bajema IM, Cid MC, Crestani B, Hauser T. EULAR/ERA-EDTA recommendations for the management of ANCA-associated vasculitis. Ann Rheum Dis. 2016;75:1583-94.

42. Hellmich B, Agueda A, Monti S, Buttgereit F, de Boysson H, Brouwer E, et al. 2018 Update of the EULAR recommendations 
for the management of large vessel vasculitis. Ann Rheum Dis. 2020;79:19-30.

43. Adizie T, Moots RJ, Hodkinson B, French N, Adebajo AO. Inflammatory arthritis in HIV positive patients: a practical guide. BMC Infect Dis. 2016;16:100.

44. Fink DL, Hedley L, Miller RF. Systematic review of the efficacy and safety of biological therapy for inflammatory conditions in HIV-infected individuals. Int J STD AIDS. 2017;28:110-9.
45. Ceribelli A, Motta F, De Santis M, Ansari AA, Ridgway WM, Gershwin ME, et al. Recommendations for coronavirus infection in rheumatic diseases treated with biologic therapy. J Autoimmun. 2020;109:102442. https://doi.org/10.1016/j.jaut.2020.102442.

Publisher's Note Springer Nature remains neutral with regard to jurisdictional claims in published maps and institutional affiliations. 